\title{
PEQUENO ENSAIO SOBRE RESISTÊNCIA: A POTÊNCIA DA RECUSA - BARTLEBYS INDÍGENAS E OS MOVIMENTOS ABERRANTES
}

ANTONIO HENRIQUE MAIA LIMA ${ }^{1}$

$P U C / S P$

SILVANA TÓTORA ${ }^{2}$

$P U C / S P$

RESUMO: Propomos um ensaio de resistência a partir da criação de um pensamento que não se limita a comunicar o que já se sabe, mas como experiência modificadora dos jogos de verdade, destacando os povos indígenas, particularmente do Mato Grosso do Sul - os Guarani-Kaiowáfrente ao aparelho de Estado aliado ao agronegócio. Nossa conclusão se expressa como um manifesto de resistência e produção de um bloco de devires em favor de uma vida outra e uma nova terra.

PALAVRAS-CHAVE: resistência, recusa, povos indígenas, movimentos aberrantes, GuaraniKaiowá.

ABSTRACT: We proposed an essay on resistance since the conceiving of a thought that is not limited to communicating what is already known but to as a modifying experience of power relations. We highlighted the resistance experience of indigenous peoples from Mato Grosso do Sul (Guarani- Kaiowá) facing the State apparatus allied with agribusiness. Our conclusion is expressed as a resistance manifesto and as a block of becoming in favor of another life and a new land.

KEYWORDS: resistance, refusal, indigenous peoples, aberrant movements, Guarani-Kaiowá.

\footnotetext{
${ }^{1}$ Doutorando em Ciências Sociais pela Pontifícia Universidade Católica de São Paulo (PUCS/SP). E-mail: henrick_maia@hotmail.com.

${ }^{2}$ Doutora em Ciências Sociais pela Pontifícia Universidade Católica de São Paulo (PUCS/SP), docente do Departamento de Política e do Programa de pós-graduação strictu sensu em Ciências Sociais da PUC/SP. E-mail: stotora@uol.com.br .
} 


\section{INTRODUÇÃO}

Chamamos este trabalho de "pequeno ensaio"3 sobre resistência porque procuraremos demonstrar como "povos do sul" resistem, nas diferentes esferas da vida, ao avanço do capitalismo sobre suas terras e territórios originários, sobre seus corpos, sobre sua cultura e sobre sua religião. Este avanço ao qual nos referimos se sistematiza de diferentes formas em diferentes lugares. No entanto, a figura mais aparente é a do agronegócio. Assim, ensaiamos sobre as resistências dos povos do Cone Sul do Mato Grosso do Sul frente às políticas de desenvolvimento operadas pelo Estado brasileiro, na tentativa de apreender os reflexos desse jogo de forças nas diferentes dimensões da vida - corpo, sexo, raça/etnia, modos de viver, modos de pensar - que exprimem distintas maneiras de resistir, muitas das quais sequer podemos ainda imaginar, quiçá demonstrar. No presente texto enfatizamos a questão da resistência no campo das territorialidades e a potência que da atitude de recusa diante desse "jogo de forças".

A questão da resistência dos povos nativos americanos frente à dominação europeia- não somente política, mas histórica, epistemológica e existencial, fornecendo modelos de vida que penetram em todos os aspectos da vida - é um sintoma de recusa radical que persiste por mais de 500 anos e que, nas últimas décadas - especialmente após os eventos de 1968, acentuando-se com os conturbados anos 1990 e com a ebulição de diversos movimentos nos últimos anos em todas as partes do mundo -, tem sido reoxigenada por uma diversidade de pensadores. A primeira questão que permeia este ponto é: Quid vitae? Que vida? E, a partir dela, defenderemos o caráter aberrante do que estamos chamando de movimento político indígena. Nesse sentido:

A Terra é percorrida por um combate desigual entre as resistências nômades e o poder de captura dos Estados, aliados da destruição englobante engendrada pelo capitalismo. Como escapar, ou criar um novo modo de

\footnotetext{
${ }^{3}$ Seguimos a sugestão de Foucault (1998, p. 13) acerca do ensaio como um trabalho crítico do pensamento sobre o próprio pensamento e a busca por pensar diferentemente, em vez de reforçar o que já se sabe. $\mathrm{O}$ ensaio se coloca, neste caso, como uma experiência modificadora dos jogos de verdade e não como um mero recurso de comunicação do que já se sabe.
} 
povoar a terra, conectado às minorias? Como se tornar capaz de agir politicamente? [...] Quid vitae? (TÓTORA, 2017, p. 111).

Como disse Le Breton (2017), as condutas de risco são um chamado à vida. Este é o limiar das aberrações. O corte, o traçado, a linha de fronteira entre o ordinário e o extraordinário, o molar e o molecular ${ }^{4}$, entre o "estar vivo" e o "ser vivo". Assim devemos questionar: de que vida se fala? Que vida se vive? Que vida se pode viver?

Antes de qualquer coisa, a filosofia de Deleuze é uma filosofia dos movimentos aberrantes. Tais movimentos constituem a mais alta potência de existir, ao passo que as lógicas irracionais constituem a mais alta potência de pensar. Os movimentos aberrantes constituem o problema específico de Deleuze e podem ser a razão de sua aliança com Guattari. Esses movimentos têm por característica precípua o fato de extrapolarem o exercício empírico das faculdades, forçando-as ao limite de si mesmas. Eles traçam linhas de fuga destruindo tudo que se podia, inclusive arriscando-se a destruírem a si próprios, pois ameaçam a vida tanto quanto libertam suas potências (LAPOUJADE, 2015).

As correntes de pensamento às quais nos aliamos se propõem, primeiramente, a buscar uma linha de fuga $^{5}$ ao sistema Capitalismo/Modernidade - que, respectivamente, seria um mundo por vir no pensamento de Deleuze e Guattari; e a Transmodernidade, a partir dos conceitos elaborados pelos autores decoloniais: uma superação da modernidade eurocentrada, mas que não é a pós-modernidade. Nesse aspecto são correntes de pensamento que fazem uma ode à resistência. A partir disso, tentaremos abordar a resistência dos povos indígenas, com destaque para as lutas dos Gurarani-Kaiowá, que vêm sofrendo profundamente com o assédio do sistema capitalismo/modernidade há

\footnotetext{
${ }^{4}$ Segundo Deleuze e Guattari (1996), todas as sociedades - mas também os indivíduos - são atravessadas por duas segmentaridades - inseparáveis, mas distintas -: uma molar e outra molecular. As linhas molares recortam os corpos e coletivos em segmentos binários: homem-mulher, negro-branco, criança-adulto etc. Esses segmentos também implicam dispositivos de poder que fixam territórios e identidades. Esses segmentos são sobrecodificados em saberes, línguas e enunciados dominantes de uma sociedade e poderes de Estado que os mantêm. As linhas moleculares são fluxos de intensidades constituindo devires, blocos de devires, marcando contínuos de intensidades e não possuem o mesmo ritmo da história. Essas linhas são mutantes e não são sobrecodificadas pelo Estado. As grandes oposições ou rupturas são negociáveis, "mas não as pequenas fissuras moleculares imperceptíveis e que vêm do Sul" (Deleuze, 1998, p. 153).

5 "E fugir não é partir em retirada, e sim não temer ou esperar, mas buscar novas armas" (DELEUZE, 1990, p. 2).
} 
séculos, movimento que se acentuou nos últimos anos. Com base na novela de Melville, faremos uma apropriação do personagem Bartleby como recurso expressivo para a análise da resistência dos GuaraniKaiowá.

O conquistador europeu ao mesmo tempo em que territorializa para si um novo mundo ou novas terras, desterritorializa as do outro e, com isso, destrói o modo de existência dos nativos. O território, antes de tudo, é uma expressividade, uma zona de experiência: "[...] marca constituinte de um domínio, de uma permanência" (ZOURABICHVILI, 2004, p. 22-23) - e não de um sujeito -, o território designa as relações de propriedade ou de apropriação - e, concomitantemente de distância em que toda identificação subjetiva se fundamenta - "um ter mais profundo que o ser" (DELEUZE; GUATTARI, 1997, p. 123). Nesse sentido, Deleuze (1994) é enfático: "território é o domínio do ter [...] não há território sem um vetor de saída do território e não há saída do território, ou seja, desterritorialização, sem, [que] ao mesmo tempo, [haja] um esforço para se reterritorializar em outra parte". ( $A$ de Anima). Desterritorializar é o movimento pelo qual se deixa o território (ZOURABICHVILI, 2004, p. 22). E esse vetor de saída para a desterritorialização indígena seria o invasor europeu. Outro sentido para território seria o atribuído por Günz (apud Haesbaert; Bruce, 2002) - tal sentido seria mais etológico: "o ambiente de um grupo (por exemplo, um coletivo de lobos, de ratos ou um grupo de nômades) que não pode por si mesmo ser objetivamente localizado, mas que é constituído por padrões de interação por meio dos quais o grupo ou coletivo assegura certa estabilidade e localização". Nesse aspecto o território pode ser constituído tanto por uma pessoa quanto por uma comunidade: um corpo-político. O que ambos os conceitos apresentados têm em comum pode ser resumido na seguinte expressão: não se trata de viver "no território", mas de viver "o território".

$\mathrm{Na}$ medida em que a América é desterritorializada e reterritorializada pelos europeus, vai sendo, por sua vez, reterritorializada pelos seus habitantes nativos. Territorializar é ritmo tornado expressivo ou de componentes de meios tornados qualitativos, ou seja, um processo de constituição do tempo e do espaço (ZOURABICHVILI, 2004, p. 23). Se sob um grande plano de imanência - 
traçados intensivos de tempos e espaços - há um território primordial a Terra -, sob a perspectiva dos conquistadores após o "descobrimento", com o fim de justificar a sua conquista, é traçada uma linha divisória imaginária constituindo dois territórios: um Norte de onde eles provêm e um Sul que está por ser ou em processo de ser por eles territorializado tornado território. Por sua vez, outra seria a perspectiva do indígena cujo território (sua casa, a Terra) vem sendo territorializado por outro e, portanto, também por ele alterado. Essa relação pressupõe a recíproca transformação/afetação dos sujeitos (processos de subjetivação) e, portanto, dos seus respectivos territórios.

Para além do grande território - a Terra - há o caos - tanto sob a perspectiva do conquistador quanto do indígena. Daí a ideia aqui posta de que o território no sentido amplo, a Terra, muda segundo a perspectiva, seja a do conquistador, seja a dos indígenas. Também entre os animais existem aqueles de território e os sem território. Entre os indígenas e os animais existem relações que são devires. As linhas de fronteira se sobrepõem. E um devir não é imitar um animal, mas tornarse com ele outra coisa. E os devires são incompreensíveis pelos conquistadores, pois a sua lógica é a das demarcações, domínios, distâncias e identidades oponíveis. Um território é, sob a perspectiva indígena, devires animal, floresta, plantas, rios, céu. E é próprio de todos os devires serem minoritários, ou seja, fazerem fugir ou desterritorializarem os estratos ou códigos dominantes.

Experimentar os devires - ou, em particular, os devires animais é um modo de partilhar com eles um experimento artista na produção de territórios. Nessa direção, Deleuze (1994), por ocasião de sua entrevista à Claire Parnet, afirma:

Há os animais de território, há animais sem território, mas os animais de território são prodigiosos, porque constituir um território, para mim, é quase o nascimento da arte. Quando vemos como um animal marca seu território, todo mundo sabe, todo mundo invoca sempre... as histórias de glândulas anais, de urina, com as quais eles marcam as fronteiras de seu território. O que intervém na marcação é, também, uma série de posturas, por exemplo, se abaixar, se levantar (DELEUZE, 1994, $A$ de Anima). 
O que acontece quando os animais têm seus territórios transgredidos? O animal resiste! Este é o tom do presente texto: resistência. E resistir é criar novos territórios também para o pensamento.

\section{UM BOM ENCONTRO: O PENSAMENTO DECOLONIAL E A FILOSOFIA DOS MOVIMENTOS ABERRANTES}

Nas últimas décadas uma literatura fértil e polêmica surgiu no horizonte da filosofia e das ciências sociais latino-americanas: os estudos decoloniais, a partir da cisão com outra literatura fértil e polêmica: os estudos pós-coloniais. Esta literatura impinge uma crítica radical ao pensamento moderno e à modernidade de uma forma geral, que, segundo os mesmos, se estruturou a partir de uma lógica de colonialidade, isto é, exploração, dominação e colonização em todos os sentidos da vida: das relações humanas às epistemologias, do trabalho à política. Dentro dessa chave de pensamento, Santos (2010) teoriza a existência de duas humanidades: uma humanidade que se predispõe a ser universal e uma humanidade constituída por esta - a exemplo da construção do Sul, que é habitado por uma "quase" humanidade, um território selvagem habitado por seres selvagens -, a princípio, e que depois passa a constituir a si própria como reflexo das relações de colonialidade (ser, saber, natureza, etc.) que o autor chamou de Humanidade Sacrificial. Esta ideia é atingida a partir do conceito de "negação da humanidade" em Frantz Fanon, nos célebres Peles negras, máscaras brancas (1952) e Os condenados da Terra (1961).

[...] assim a exclusão ${ }^{6}$ torna-se simultaneamente radical e inexistente, uma vez que seres sub-humanos não são considerados sequer candidatos à inclusão social. A humanidade moderna não se concebe sem uma subhumanidade moderna. A negação de uma parte da

\footnotetext{
${ }^{6}$ Apesar de Boaventura Santos usar as terminologias "exclusão" e "inclusão" que são carregadas de uma discussão profunda e acalorada na sociologia nós propomos uma leitura ou interpretação a partir dos vocábulos "negação" e "reconhecimento". "Humanidades de menor importância", provavelmente, dentro da chave de pensamento de Giorgio Agamben (2007) em Homo Saccer: o poder soberano e a vida nua.
} 
humanidade é sacrificial, na medida em que constitui a condição para a outra parte da humanidade se afirmar enquanto universal (SANTOS, 2010, pp. 30-31).

Dentro da proposta decolonial, a modernidade deve seu triunfo à conquista do Sul pelo Norte (não necessariamente o Sul e o Norte geográficos) e todas as suas consequências. Se há uma data para marcar a modernidade esta é 1492, com o "descobrimento" para os europeus da América. O que propomos é uma interpretação destes grandes hemisférios como territórios, nos termos deleuze-guattarianos. Assim, seria proveitoso reavaliar a concepção de Santos destes espaços separados por uma linha abissal sob o olhar daqueles autores, já que o próprio Santos (2010, p. 31 ) esclarece: “a criação e ao mesmo tempo a negação do outro lado da linha fazem parte integralmente de princípios e práticas hegemônicas". Norte e Sul em Santos e nos demais autores decoloniais - respeitados seus respectivos posicionamentos teóricos, políticos e conceituais - são territórios (em sentido literal, político, mas também além dessa delimitação: uma categoria de constituição de sujeitos) construídos pelo conquistador europeu que se justapõem aos territórios outros em diferentes esferas para cumprirem mais ou menos um mesmo objetivo: justificar a dominação. Assim, norte/sul, metrópole/colônia, velho/novo mundo, civilizado/selvagem, eu/outro, etc, são todos construtos que justificam o avanço colonial, uma lógica ordenada de apropriação e violência. Uma cartografia de poder colonial baseada em modos dicotômicos e binários de pensar.

À luz dos conceitos de Deleuze e Guattari: que vemos nesse processo senão os movimentos territorializantes/desterritorializantes? A constituição de um território europeu na América implicaria na sobreposição dos territórios dos nativos americanos - não só em sentido amplo como, principalmente, em sentido estrito, isto é, o território enquanto domínio do ter, mas também, de constituição do ser. "Volto para o meu território, que eu conheço, ou então me desterritorializo, ou seja, parto, saio do meu território" (DELEUZE, 1994, O de ópera). Isso vale para o conquistador e para o conquistado. Quanto ao europeu que chega à América como "perdido", retorna à Europa como “dominador". Quanto aos indígenas que se encontram na América como "formações sociais", 
em sua maioria "selvagem", nos termos de Deleuze e Guattari têm de passar à formação "nômade", com a chegada do outro, e mais: "tem ameaçado seu território", "já não é mais seu território", "é preciso reterritorializar-se". Nunca se retorna o mesmo quando se aventura fora do território. "São duas formas de distanciamento de si: dilaceramento de si ao qual não se cessa de retornar como um estrangeiro, uma vez que ele está perdido. [...] extirpação de si ao qual só se regressa como estrangeiro, desconhecível ou tornado imperceptível (ZOURABICHVILI, 2004, pp. 50-51). Há nesse ponto a dupla afetação que torna estrangeiro o desterritorializado/reterritorializado. O movimento dos afetos percorre tanto o europeu quanto o indígena, de modo que ambos se reterritorializam numa "outra coisa".

Lapoujade (2015) anima a discussão quando lembra que o filósofo bicéfalo Deleuze/Guattari, considerando as interações entre as multiplicidades, distingue em dois momentos de sua trajetória intelectual uma variedade de "formações sociais". No Anti-Édipo os autores falam em três configurações: o selvagem, os bárbaros e os civilizados. Nos Mil Platôs os autores diferenciam cinco formações sociais: as sociedades linhageiras, os Estados imperiais, as cidades, os nômades e as organizações internacionais. As linhageiras são sociedades quem formam territórios, lançam linhas, criam territórios que perduram o quanto perdurarem os seus recursos. São itinerantes. Os Estados imperiais se sedentarizam sobre a Terra desterritorializando os territórios primitivos para formar a unidade de uma terra. Traçam as fronteiras, erguem as muralhas, controlam o deslocamento das populações. As cidades são "pontos de encontro", não são nem sedentárias nem itinerantes, tudo funciona num circuito mercadológico. Já as sociedades nômades são inseparáveis de uma "máquina de guerra" que distribui a população num espaço liso. Os nômades são desterritorializados e, sobretudo, desterritorializam a Terra. As organizações internacionais não são formações sociais, mas circulam entre elas. São por Deleuze chamadas de ecumênicas, pois tal como o cristianismo e o capitalismo "não procede por homogeneização progressiva, nem por totalização, mas por tomada de consistência ou consolidação do diverso enquanto tal [... ]Todas as formações sociais coexistem num único e mesmo campo de interações" (LAPOUJADE, 2015, p. 229-230). 
O fato de Deleuze e Guattari atribuírem uma classificação inicial das formações sociais em selvagens, bárbaros e civilizados pode dar a falsa impressão que os autores possuem alguma aliança intelectual com o evolucionismo. No entanto, é o seu contrário. Enfatiza Lapoujade (2015, p. 230) "não se passa dos nômades aos sedentários, dos caçadorescoletores aos agricultores [...] Todos os tipos de organizações sociais são dados ao mesmo tempo, coexistem num mesmo espaço-tempo, como atestam a história e a pré-história". Assim, a chegada à América de um aparelho de Estado nos moldes imperiais não é inédito, dado que já havia configurações similares por aqui, como o Império Inca, por exemplo.

Pela chave conceitual das epistemologias do Sul todas as formas de dominação e classificação também coexistem, inclusive historicamente. O Estado ao associar-se ao capitalismo - ou mesmo um proto-estado com um protocapitalismo - institui um elemento constitutivo e específico de poder que permeia todas as esferas da vida: a classificação racial/étnica. Assim, a modernidade parte de uma ideia mitológica de uma Europa-pré-existente. E como tal, os europeus atribuíram "uma concepção de humanidade, segundo a qual a população do mundo se diferenciava em inferiores e superiores, irracionais e racionais, primitivos e civilizados, tradicionais e modernos" (QUIJANO, 2010, p. 74-75). Tal "Europa" é metafórica e discursiva, no sentido de que remete a tudo que se estabeleceu como uma expressão da Europa: como, por exemplo, a formação social "Estado-imperial" de Deleuze e Guattari. Adverte ainda Anibal Quijano (2010) que o modelo Estado-nação se torna a unidade de análise e único enfoque válido do conhecimento sobre o capitalismo. O que não era "da nação", a exemplo dos índios e dos negros, era do "império" e deveria estar à disposição da nação. Assim traça-se a linha abissal de Santos (2010): um território civilizado e um território selvagem onde tudo era permitido em prol do bem da "nação". Em termos de humanidade, uma sacrificial e outra - que se pretende - universal. No território selvagem - abaixo da Linha do Equador - "tudo se podia". Ora, os índios e os negros não foram criações dos colonizadores? Eis uma das cisões estabelecidas pelo europeu colonizador branco. Seu poder e domínio dependem da manutenção dessa cisão, dessa diferenciação radical.

A questão que nos leva a traçar o paralelo entre este conjunto de 
autores é a de haver contemporaneidade ou coexistência das formações sociais, o que em ambos os casos, de certa forma, advoga para outra ciência: descolonizada, para Santos e Quijano e uma "ciência menor"7, segundo Deleuze e Guattari (2012). Diferente do que postulava a epistemologia dominante no amanhecer da modernidade, segundo a qual haveria seres-humanos menos humanos se comparado ao "padrão" europeu e que estes, por consequência, eram "inferiores" e poderiam legitimamente ser "usados" pelos "superiores". Todas as aspas são necessárias quando falamos deste assunto. Assim, haveria uma distância entre o europeu e o nativo - tido como selvagem -, uma distância histórica - mas também virtual - no terreno dos devires e das potências, que mantinha os povos americanos sempre degraus abaixo dos povos europeus. Esta ideia é rechaçada a seu modo pelas duas correntes de pensamento aqui analisadas. Há a coexistência histórica - diriam os decoloniais - e virtual, no terreno dos devires e das potências - diriam Deleuze e Guattari e dizem seus leitores, como Viveiros de Castro nas Metafísicas Canibais [2015]). Uma questão de fundo posta entre as correntes é que os primeiros afirmam que a coexistência é histórica e os últimos que é aiônica ${ }^{8}$. Nós entendemos que é uma coexistência histórica e aiônica. O encontro aiônico não se limita ao traçado da história cronológica.

Para a corrente decolonial essa coexistência é histórica. Por exemplo, todo o repertório da ideia de desenvolvimento sustentável trazida à discussão em pleno século XX pela epistemologia dominante, isto é, pelo projeto moderno ocidental, já era presente nas epistemologias subalternas, à sua maneira, dos mais variados povos indígenas do Sul epistemológico. No entanto, o projeto moderno oferece uma forma colonial de "desenvolvimento" que desconsidera e desqualifica o que vem dos nativos tornando esse saber um não-saber: um pensamento "de" selvagem, que não mereceria ser levado em consideração. Os saberes dos indígenas foram assim suprimidos e silenciados, traçando a diferença

\footnotetext{
${ }^{7}$ Deleuze e Guattari introduzem o conceito de "ciência menor" ou "ciência nômade", aquela que, ao contrário de "reproduzir", "busca seguir um fluxo num campo de vetores no qual singularidades se distribuem com outros tantos 'acidentes' [que são problemas]" (Deleuze e Guattari, 2012, p. 42). A "ciência menor", diferentemente da "ciência régia" ou de Estado, não está destinada a tomar o poder e suscita mais problemas do que pode resolver, pois a solução desses problemas caberia a uma atividade coletiva não científica (Ibid. p. 44).

${ }^{8}$ Aiônico diz respeito a um tempo não medido, diferentemente do tempo cronológico ou histórico.
} 
colonial (GROSFOGUEL, 2010).

Segundo Lapoujade (2015, p. 231)

\begin{abstract}
"há um campo não histórico em que todas as potências da "Máquina Social" coexistem virtualmente [...] A formaEstado, a forma-Cidade, o nomadismo já estão presentes nos primitivos, mas como potencialidades que a potência de sua organização social tem por função conjurar [...] Diríamos o mesmo do Estado, que contém nele as potências das outras formações sociais, ainda que para reprimi-las ou desviá-las em seu proveito".
\end{abstract}

Nesse sentido, como anteriormente comentamos, já havia na América os Estados-imperiais, mas também há na abordagem europeia do Novo Mundo, "desviada a seu proveito", a forma das sociedades linhageiras, que territorializam e reterritorializam a depender da existência ou não de recursos. Por exemplo, há também a formaçãocidade que cria os circuitos comerciais, além da própria forma-Estado. Os Guarani-Kaiowá e os povos indígenas do Cone Sul do Mato Grosso do Sul são presenças vivas da forma-nômade que afrontam e ameaçam como "máquina de guerra" a forma-Estado. Nesse caso, segundo Deleuze e Guattari (2012), a formação nômade é uma formação que procede de maneira muito diferente da forma-Estado: esta segunda se preocupa em "conservar" ao passo que a primeira é uma metamorfose de máquina de guerra, pois opera, por ocupação. Assim a forma nômade é a resistência primeira da territorialização da forma-Estado.

Cumpre destacar que nômade, para Deleuze e Guattari, é um conceito abrangente, compreendendo, inclusive, um modo de pensar como potência criadora em detrimento de uma pura recognição dos valores estabelecidos e seus poderes. Ao contrário, existe no pensamento nômade um desprezo pelo poder e suas encenações. A "máquina de guerra" é irredutível ao aparelho de Estado e à sua lógica sedentária de domínio. Os nômades inventaram a máquina de guerra não com objetivo da guerra, embora as batalhas possam ocorrer em certas condições, particularmente no choque com os Estados. A guerra primitiva, segundo Clastres (apud Deleuze; Guattari, 2012), visava não o domínio, mas a conjuração do aparelho de Estado. Quando o Estado se apropria da 
máquina de guerra ela muda de natureza e função, passa a ter a guerra como objetivo, a ser dirigida contra os nômades e contra todos aqueles que visam destruir os estados, como também passa a atuar na luta entre estados com vista ao domínio e destruição de uns pelos outros.

A máquina de guerra se constitui contra o aparelho de Estado. A primeira configura-se por espacialidades diferentes e opera em fluxos que se movem por ocupação e por deslocamentos em um espaço não estratificado, ao passo que o segundo opera como corpo estratificado. A máquina de guerra é sempre exterior à soberania, ao passo que o Estado se articula sob a soberania política. A máquina de guerra tem outra justiça, anterior ao direito codificado no aparelho de justiça do Estado. Em suma, a máquina de guerra é irredutível ao aparelho de Estado, pois, como multiplicidades nômades, constitui-se em pura potência.

Na Genealogia da Moral, Nietzsche (2013c) constrói sua tipologia do guerreiro, diferentemente do soldado estatal. Trata-se de uma força criadora de novos valores, um tipo pré-histórico e contemporâneo ao mesmo tempo: coexiste com a forma-estado, mas como seu Fora. A máquina de guerra percorre um espaço ainda não tomado pelo Estado: na zona de fronteira. Se a máquina é guerrilha o Estado é soldado, pois a forma-Estado é por demais burocrática e hierárquica. O guerreiro ou o nômade diferem do soldado, pois ao contrário deste - que possui valores de Estado -, aqueles possuem valores de resistência: ideais e moral diferentes. Para o Estado e para a Modernidade, cuja configuração política básica e o discurso ideopolítico se equivalem reciprocamente, os valores nômades ou os valores dos guerreiros são valores toscos, loucos, de fera, de pecador, de selvagem, de bárbaro, de fora. O aparelho de Estado visa à segurança e defesa desse Fora ameaçador. Sob o ponto de vista do Estado o caos está nas fronteiras do seu território. Aí estão os selvagens, os nômades, os bárbaros: o que existe de fato é uma coexistência entre a máquina de guerra e Estado (Deleuze e Guattari, 2012), ou seja, entre os nômades e os sedentários, entre os nativos americanos e os conquistadores europeus. Essa coexistência, esse "contra", leva ao "traçado abissal" sugerido pelos autores decoloniaisEm uma prancha de análise histórica é verdade que se mantêm como diferença quando passamos à análise da Ciência do Estado ou Ciência Régia e da ciência menor, em consonância com os conceitos de Deleuze e Guattari (2012), 
como também a divisão entre as Epistemologias Dominantes e Epistemologias do Sul para os pensadores decoloniais. Se a formanômade é a resistência primeira à forma-Estado, o indígena também pode sê-lo em relação ao conquistador. Resistir é algo que os povos indígenas são exatos especialistas!

\section{A POTÊNCIA DA RECUSA: BARTLEBYS INDÍGENAS}

Nossa compreensão de recusa e de uma potência da recusa se perfila ao memorável texto de Sztutman (2013).Com a trajetória de vida do personagem Bartleby, o escrivão, tentaremos demonstrar como a recusa pode ser ativa. Antes de qualquer coisa, quem foi Bartleby? Bartleby foi protagonista de um conto de Herman Melville intitulado Bartleby, O Escrivão publicado em 1853. Esse personagem tem inspirado diversos autores ao tratarem de uma atitude de recusa. Essa atitude de recusa está também profundamente presente tanto em Deleuze e Guattari quanto no Projeto Decolonial e, por isso, pode nos servir como fio condutor de um diálogo quanto à resistência indígena às relações de colonialidade, ao sistema Capitalismo/Modernidade, à Epistemologia Dominante, à Ciência Régia, etc. Essa atitude se expressa por meio da enigmática afirmação: preferia não fazer. Como salientam Hardt e Negri (2001, p. 222-223) "O personagem de Melville se encaixa numa longa tradição de recusa ao trabalho [...]. Mas Bartleby, radicaliza". "O comportamento de Bartleby é desconcertante, em parte porque se mostra tão calmo e sereno, mas porque sua recusa é tão decidida que se torna absoluta". A simplicidade de Bartleby no conto leva-nos a crer ser este um "tal medíocre", preguiçoso, afinal sua recusa se dava no ambiente de trabalho, preferia não cumprir às ordens de seu patrão. Bartleby se recusa, portanto, à autoridade de seu patrão, não necessariamente ao trabalho. No conto, Bartleby morre de fome, por se recusar a comer na prisão.

A recusa extrema à autoridade, levada a cabo por Bartleby, terminou com a morte do personagem. Assim, retomemos a ideia boaventuriana de Humanidade Sacrificial: para Santos (2010) o sacrifício de uma parte da humanidade é condição para a universalidade da outra parte. Em Deleuze e Guattari o desterritorializado por natureza é o 
nômade, que, no entanto, sempre está em movimento, reterritorializando-se. Reterritorializar, portanto, é condição para o desterritorializar. Além do território há o caos. A máquina de guerra nômade tem a potência de destruir tudo que impede o livre fluxo das multiplicidades, conforme Lapoujade (2015, p. 249) comenta sobre Mil Platôs: "tudo muda quando o aparelho de Estado logra se apropriar da máquina de guerra". O colonizador/conquistador europeu o fez. O Estado moderno desvirtua a máquina de guerra nômade e passa a utilizála para impor sua organização e seus objetivos. Desterritorializa o nômade e reterritorializa a terra "à força". Segundo Deleuze e Guattari (2012, p. 75) a "[...] derrota dos nômades foi tal, tão completa, que a história identifica-se com o triunfo dos Estados. Assistiu-se, então, a uma crítica generalizada que negava aos nômades toda inovação, tecnológica ou metalúrgica, política, metafísica". O Estado se apodera da máquinanômade negando a humanidade do nômade: "tentou-se aplicar à máquina de guerra uma categoria propriamente militar (a de "democracia militar"), e ao nomadismo uma categoria propriamente sedentária (a de feudalidade)" (DELEUZE; GUATTARI, 2012, p. 76). O Estado moderno então impinge uma lógica global de guerra, sob um disfarce de paz absoluta: "[...] uma paz fundada no superarmamentismo e na ameaça de um confronto apocalíptico. [...] a nova máquina de guerra persegue novos objetivos de ordem econômica, financeira e tecnológica [...]" (LAPOUJADE, 2015 , p. 250).

Ora, podemos interpretar esse novo sentido dado pelo Estado moderno à máquina de guerra, principalmente em seu braço econômico, como expressão dos desenvolvimentismos ou, como diriam os decoloniais, do "discurso desenvolvimentista". A paz, a segurança e o desenvolvimento passam a ser a razão da máquina operada pelo Estado moderno. A lógica de paz pela guerra é imposta e a máquina se torna securitária, mundial e globalizada, tendo como função a paz, mas sem perder sua potência de destruição. Com as devidas vênias: a máquina de guerra capturada pelo aparelho estatal opera uma organização mundial da miséria e da opressão, provocando, como destaca Lapoujade (2015), fome, guerras locais endêmicas, deportações, multiplicação dos guetos e das favelas. Em suma, uma operação de limpeza, segregação, purificação étnica, econômica e social: o despovoamento da Terra. 
Pensamos que essa reflexão se aproxima do discurso decolonial na medida em que, por outros termos, chegam à conclusão similar. A humanidade sacrificial coincide com os povos da terra dominada, os povos do sul, do "terceiro mundo", do "submundo". A velha ideia colonial em que "tudo se podia abaixo do Equador" é tão contemporânea como nunca. A territorialização do Sul pelo Norte é um processo que se inicia com a chegada de Colombo, com a modernidade, mas, tal como esta, ainda não cessou. A concretização do projeto moderno seria, do nosso ponto de vista, parecida com o que Deleuze e Guattari (2012) chamam de controle absoluto da Terra, desterritorialização de vez. A morte das multiplicidades, da Terra inteira, é a conclusão da modernidade: a universalidade, o fim de toda singularidade, a absorção das diferenças, o englobamento de tudo e de todos aqueles que ainda resistem. A ciência moderna ou régia ciência é um instrumento: a engenharia desta máquina dominada.

O que caracteriza a máquina de guerra nômade é que ela só destrói o que impede seus processos de desterritorialização - locais, é claro, mas absolutos; ela transforma a morte e a destruição em potências positivas, na medida em que elas favorecem uma livre circulação das intensidades num espaço liso. Ela estabelece um papel positivo com o absoluto da desterritorialização; talvez por isso os nômades não saibam o que fazer com as terras conquistadas. Tudo se reverte com a máquina de guerra capitalista pós-fascista. Ela também opera uma desterritorialização absoluta, mas global, englobante, desta vez fazendo da morte e da destruição potências negativas e mortíferas. Ela transforma a função da morte. Tudo se joga, portanto, no nível da desterritorialização e do papel que nela se desempenha o absoluto. Num caso [o primeiro] o absoluto se faz aqui e agora, local e momentaneamente, sempre de maneira intempestiva; no outro caso [o segundo] o absoluto está em toda parte, permanentemente ele desempenha o papel de fundamento. Num caso [o primeiro] a desterritorialização consiste em criar uma nova terra, aqui e agora, que segue uma linha de fuga positivamente destruidora; no outro 
caso [o segundo] pelo contrário, a desterritorialização segue uma linha de destruição mortífera, de abolição que cerca a terra em toda parte, como um anel de Saturno (DELEUZE; GUATTARI apud LAPOUJADE, 2015, p. 253).

O projeto moderno operado pela máquina de guerra do Estado pretende o absoluto. Pela linha de pensamento decolonial há que superálo em prol de uma Transmodernidade onde o universal seria a diversidade radical. O contrário do projeto moderno, pelo menos em tese, que gira em prol de uma universalidade onde o universal é o uno. Em Deleuze e Guattari as singularidades são o estereótipo da potência. Deste modo a resistência é a forma de manter vivas todas as formas de singularidade, tal como as diversidades. Temos a convicção que os indígenas e todos os povos do Sul epistemológico são os resistentes por excelência, tal como os nômades e sua máquina de guerra positiva. Resistir é fazer a guerra nômade, no local, no pequeno, no menor, uma "guerra de guerrilha" como diriam Deleuze e Guattari (2012).

Retomemos a alegoria de Bartleby. O que seria um bartleby indígena? E a recusa radical? Justamente a recusa radical é o absoluto da máquina de guerra nômade, a potência do nomadismo em resistir, como nos lembra Lapoujade (2015); ao contrário da máquina de guerra capturada pelo aparelho de Estado, que é dotada da força de um poder que destrói as relações sociais que não são capitalistas, que multiplica a fome e a guerra, que torna a terra inabitável. Segundo Deleuze e Guattari (2012 p. 114), "os fatores que fazem da guerra de Estado uma guerra total estão ligados ao capitalismo". E uma guerra total contra os povos do Sul. E não seria esse o modo de exercer o poder do desenvolvimentismo e seus defensores? Mas existem inúmeras formas de resistência. Peguemos novamente Boaventura de Sousa Santos (2003) e o sacrifício de sua outra humanidade.

Na sua versão genocida sacrificial, o neoliberalismo é uma mistura de radicalização do mercado, neoconservadorismo e fundamentalismo cristão. A sua pulsão de morte tem assumido várias formas, desde a ideia das "populações descartáveis", para referir os cidadãos do Terceiro Mundo inaptos a serem explorados como operários e 
consumidores, até o conceito de "danos colaterais", para designar a morte de milhares de civis em consequência da guerra (SANTOS, 2003).

A crítica decolonial denuncia a morte sacrifical como um desdobramento do neoliberalismo. Um efeito da máquina-capitalista. Já dissemos o seguinte: "Se a forma-nômade é a resistência primeira à forma-Estado, o indígena também pode sê-lo em relação ao conquistador." A máquina-nômade persiste no indígena, uma espécie de devir-indígena. Existe, portanto, naquele que resiste: um devir-nômade. O sacrifício, a morte de uma parte da humanidade em prol de outra é efeito do aparelho de Estado. Novamente de forma alegórica, poderíamos descrever o processo simplesmente como um ritual de sacrifício para um Deus - um Deus Capital, onde um personagem (o Sacerdote/Humanidade Universal) imola outro personagem (o Sacrifício/Humanidade Sacrificial) para uma deidade, na ânsia ou no desejo de suas bênçãos. Viveiros de Castro (2008, p. 11), um grande aliado de Deleuze e Guattari, num pequeno texto chamou de "teologia econômica" - o que serviu de inspiração para o exemplo anterior - do desenvolvimento o que é "[...] suposto ser uma necessidade antropológica, exatamente porque ele supõe uma antropologia da necessidade: a infinitude subjetiva do homem [...]". A necessidade "universal" de desenvolver foi estratégia colonial que se transmutou em estratégia pós-colonial: relações de colonialidade.

Contra a teologia da necessidade, uma pragmática da suficiência. Contra a aceleração do crescimento, a aceleração das transferências de riqueza, ou circulação livre das diferenças; contra a teoria economicista do desenvolvimento necessário, a cosmo-pragmática da ação suficiente. A suficiência é uma relação mais livre que a necessidade. As condições suficientes são maiores - mais diversas - que as condições necessárias. Contra o mundo do "tudo é necessário, nada é suficiente", a favor de um mundo onde "muito pouco é necessário, quase tudo é suficiente". Quem sabe assim tenhamos um mundo a deixar para nossos filhos (VIVEIROS DE CASTRO, 2008, p. 11-12). 
O pragmatismo da suficiência é velho conhecido das populações indígenas. E, nesse ponto, podemos observar a forma predatória como avançam os baluartes da teologia econômica, os "(mon)santos" capitalistas sobre as singularidades destes povos. O projeto moderno continua avançando em seu caminho de universalidade, de formação de um espaço liso que abrange toda a terra, povoado por unicidade. $O$ indígena, o nômade, no entanto, resistem.

\section{CONSIDERAÇÕES FINAIS}

Bartleby deixou-se morrer de fome por conta de sua recusa em obedecer: inclusive à ordem de comer. Em 2012 um grande alarde nacional ocorreu por conta de uma polêmica "morte coletiva dos índios Gurani-Kaiowá" ou também "suicídio coletivo dos índios GuaraniKaiowá". A diferença entre os dois termos nos leva à reflexão e sob a sombra daquilo que falamos até o momento: o primeiro é a morte coletiva como resultado da intervenção, da territorialização, do avanço do aparelho de Estado, Estado este que prioriza o agronegócio e que subhumaniza, como bem exemplificou Santos (2003; 2010), uma determinada humanidade: é a morte sacrificial. O suicídio coletivo ou auto-sacrifício orquestrado e planejado, como esclarece uma nota do Conselho Indigenista Missionário (CIMI, 2012), nunca ocorreu. É fato, no entanto, que o suicídio entre as populações indígenas é um assunto recorrente, mas a lição de Bartleby, ao contrário do que parece, num primeiro momento, não nos leva a ver a morte ou o "deixar-se morrer" como recusa radical, muito embora seja uma recusa extrema. Poderíamos questionar, avançando sobre a ideia de recusa, que ainda que o fosse, não estaríamos diante de uma morte em que há um culpado? Portanto, não se trata de deixar-se morrer simplesmente, mas de resistir até as últimas consequências a um processo de captura.

Se não há outros meios, isto é, se há que se morrer de uma forma ou de outra, morrer num sentido figurativo, de se despir de si mesmo, de sua singularidade, aos poucos, morrer socialmente e espiritualmente, ser "fagocitado" ou morrer de fato, fisicamente, mas enquanto aquele que 
resistiu até o fim e "morreu" enquanto corpo como era, não como o que foi feito ou tornado. O fato é que ambas as mortes são sacrificiais, no sentido dado por Santos: uma parte da humanidade precisa morrer, para que outra possa ser universal. Sobre esse episódio específico:

Esse desalento chocou o Brasil, disparando uma campanha nas redes sociais, não livre de antagonistas engajados com preconceitos e interesses anti-indígenas. Refletia, contudo, não a ameaça de um suicídio coletivo, como foi interpretada por muitos, mas a recusa existencial de viver num mundo em que não há lugar para outros mundos que não aqueles baseados no desenvolvimento econômico e no poder do capital, a recusa de viver num mundo sem liberdade, sob ameaça contínua de violência física e moral. Recusa ativa que indica o não conformismo e a iminência da luta. [...] A ideia de uma recusa ativa foi, aliás, o grande tema perseguido pelo antropólogo francês Pierre Clastres, ao longo das décadas de 1960 e 1970, quando as forças do capital avançavam de modo gritante sobre as florestas sul-americanas, ameaçando a sobrevivência física e moral das mais diversas populações indígenas. Mas Clastres não falava simplesmente na reação dos índios ao "contato" com os brancos, falava sim de uma resistência primeira, uma resistência a todo poder de unificação, de subordinação e de coerção. Eis o sentido da "sociedade contra o Estado". [...] E toda recusa seria, antes de tudo, a recusa da identidade, da univocidade (SZTUTMAN, 2013, p. 163182 , comgrifos nossos).

Hardt e Negri (2001) nos lembram que Bartleby leva ao absoluto a política da recusa, mas esta é apenas o começo de uma política libertadora. A recusa vazia é infrutífera, é impotente. A máquina de guerra nômade opera por outros meios. Bartleby é o resistente por excelência, seu "prefiro não" é simbólico e louvável, mas a recusa radical implica em algo diferente, algo novo, outro possível, como diz Sztutman (2013) algo ativo, portanto, concluímos: criação de uma nova terra.

Negri em um diálogo com Deleuze questiona-o a respeito de como articular suas críticas a uma ação política. Por isso sua menção a 
uma "recusa infrutífera". Deleuze, no entanto, não responde ao questionamento, ignora-o, evidenciando que seu problema é outro: são os "movimentos aberrantes". A cobrança por essa articulação pressupõe a capacidade de ação dos sujeitos. Logo, já seríamos capazes de agir. Deleuze, por sua vez, questiona como se tornar capaz de agir politicamente (LAPOUJADE, 2015, p. 263). A resposta de Deleuze parece estar na gênese dos movimentos aberrantes.

O fato é que, Deleuze pode concordar com Hardt e Negri (2001) que precisamos ir além da recusa, recusar à autoridade, a globalidade, a "fagocitose", recusar o sacrifício (seja lá qual for) e, a partir dessa recusa, traçar linhas de fuga rumo a um possível. Segundo Zourabichvili (2000) "sobre o possível", Deleuze diria que não há possível antes de sua criação. "O que é possível é criar o possível". O possível chega pelo acontecimento, o acontecimento abre o possível: se trata de criar novas possibilidades de vida, um modo de existência. Uma possibilidade de vida é sempre uma diferença. Diante dessas colocações nos resta concluir que o possível é resistir e a resistência abre o possível. O possível é sempre diferença, portanto, a proliferação das diferenças é a gênese da resistência. Manterse diferente é a recusa radical e isso é o que faz dos Guarani-Kaiowá (e todos os indígenas da Terra) os resistentes por excelência: Bartlebys indígenas, pois operam a resistência como modo de vida.

Essa resistência inspiradora dos povos indígenas, e em especial dos Guarani-Kaiowá, deve nos mover enquanto pesquisadores, enquanto professores, enquanto escritores na busca desse outro possível, desse mundo por vir. Ao abordar diferentes formas de resistência, a partir de autores que não só falam sobre resistência, mas resistem enquanto práxis, não seria possível para este ensaio apenas falar de resistência, mas também, enquanto práxis, ser resistência - daí ser uma espécie de manifesto. Os autores aqui agrupados no que estamos chamando de "bom encontro" vão, antes de tudo, em direção a essas formas de resistência às quais nos referimos. Esse é o primeiro ponto em comum, que favorece o "bom encontro": elas traçam linhas de resistência à ciência moderna (ou Régia), de recusa radical à forma capitalista, à forma de Estado-Imperial (ou Nação), constatam a potência do pensamento não cientificista e do pensamento nômade ou subalterno, selvagem e investem nele como uma forma de possibilitar outra realidade, outros 
possíveis - mas essa é uma discussão que precisa ser feita em outra oportunidade.

Quid vitae? Voltando a nossa questão: que vida? E assim buscamos respostas nos episódios de suicídio registrados entre os povos do Cone Sul do Mato Grosso do Sul, com destaque aos Guarani-Kaiowá. Por que um movimento "tão" aberrante? Por mais que pareça que estamos a falar de morte, em verdade falamos de vida! A morte não se dá apenas organicamente, mas faz referência "ao que a vida faz morrer em nós para libertar suas potências (e aos perigos que essa morte faz correr)" (LAPOUJADE, 2015, p. 22). É a respeito desta morte que falamos e é ela que os Guarani-Kaiowá experienciam: de uma morte cerimonial, uma crisálida, uma metamorfose, um processo de transformação, um grito de luta, uma declaração de guerra aos aparelhos de captura de Estado. Prefiro não! Prefiro não viver nessa condição! Quid vitae? Prefiro traçar linhas que fogem dessa condição abjeta. Outra vida, aqui e agora! É por ela que lutam e lutarão. É por ela que resistem. É a potência da recusa: por um outro deste mundo, por uma vida outra.

A vida não se limita à produção de organismos, mas uma vida orgânica que atravessa o organismo e ameaça sua integridade. Um devir de morte, um devir louco, uma coisa incontrolável. Uma pulsão pela vida embrenhada por um instinto de morte. "[...] uma vida tão indiferente aos corpos que atravessa quanto aos sujeitos que transforma. [...] ela leva o sujeito a experimentações no limite do insuportável" (LAPOUJADE, 2015 , p. 22). Tal instinto de morte faz morrer tudo que não é necessário para as potências da vida.Em simultâneo, essas mortes interiores perigam levar o sujeito para um projeto de morte: um suicídio.

Isso não supõe nenhum gosto, nenhum fascínio pela morte, mas sim a percepção da vida como coextensiva à morte e aos mortos pelos quais ela nos faz passar. Se é preciso tornar a morte aberrante, "esquizofrenizar a morte" [...], é porque ela é a instância silenciosa, que, por sua vez, torna a vida aberrante, esquizofrênica, daí seu caráter coextensivo. Os movimentos aberrantes nos arrancam de nós mesmos, segundo um termo que retorna com frequência em Deleuze. Há algo forte demais na vida, intenso demais, que só podemos viver no limite de nós 
mesmos. É como um risco que faz com que já não nos atenhamos mais à nossa vida no que ela tem de pessoal, mas ao impessoal que ela permite atingir, ver, criar, sentir através dela. A vida só passa a valer na ponta dela própria. Quid vitae? (LAPOUJADE, 2015, p. 23).

Não há uma luta contra a morte, mas uma morte outra, pelo qual o capitalismo faz os homens passar e que nos transforma em mortosvivos, zumbis sem um futuro. Há um futuro possível (LAPOUJADE, p. 24). Essa resistência implica "a criação de novos espaços-tempo. Eis o sentido intempestivo herdado de Nietzsche que percorreu toda a sua obra [de Deleuze]: no tempo, contra o tempo e, espero, num tempo por vir" (TÓTORA, 2017 , p. 111 ).

Os movimentos aberrantes operam uma máquina de guerra positiva e ativa, são agenciamentos guerreiros, incorporam uma força crítica avassaladora que se expressa como um grito: um prefiro não! Um "prefiro não" à racionalidade científica, um "prefiro não" ao capitalismo, um "prefiro não" a esta condição de existência, um "prefiro não" conjugado ao "sim" à vida, ao futuro, ao novo tempo, à Nova Terra.

\section{Referências bibliográficas}

AGAMBEM, Giorgio. Homo sacer: o poder soberano e a vida nua. Tradução de Henrique Burigo. Belo Horizonte: UFMG, 2007

CASTRO-GÓMEZ, Santiago. Ciencias sociales, violencia epistémica y el problema de la "invención del otro". In. LANDER, Edgardo (comp.). La colonialidad del saber: eurocentrismo y ciencias sociales - perspectivas latinoamericanas. Buenos Aires: CLACSO, 2000.

CIMI - Conselho Indigenista Missionário. Nota sobre o suposto suicídio coletivo dos Kaiowá de Pyelito Kue. Disponível em: http://cimi.org.br/site/ptbr/?system=news\&conteudo_id=6578\&action=read Acesso em 03/2018.

CLASTRES, Pierre. A sociedade contra o Estado: investigações de antropologia política. Trad. Bernard Frey. Porto: Afrontamento, 1979. 
DELEUZE, Gilles. Pos-scriptum sur les sociétés de controle. In Pourpaler. Paris: Les Éditions de Minuit, 1990.

O abecedário de Deleuze. Entrevista concedida à Claire Parnet, 1994. Transcrição integral do vídeo. Disponível em: http://escolanomade.org/wpcontent/downloads/deleuze-o-abecedario.pdf Também em vídeo em: https://www.youtube.com/watch?v=wxIqWlrVdBc\&list=PL3KuoFAFw68mZ9Qb_Ltzj StwLxaIEC7DJ.

Conversações (1972-1990). 3. ed. Tradução de Peter Pál Pelbart. São Paulo: Editora 34, 2013. (Coleção TRANS).

DELEUZE, Gilles; GUATTARI, Félix. Mil Platôs: capitalismo e esquizofrenia. Tradução de Ana Lúcia de Oliveira (coord.). v. 3. São Paulo: Editora 34, 1996. (Coleção TRANS).

. Mil Platôs: capitalismo e esquizofrenia. v. 4. Tradução de Suely Rolnik. São Paulo: 34, 1997.

O que é a filosofia? 3. ed. Tradução de Bento prado Jr. e Alberto Alonso Munoz. São Paulo: Editora 34 (Coleção TRANS), 2010.

. Mil Platôs: capitalismo e esquizofrenia. Tradução de Peter Pál Pelbart e Janice Caiafa. v. 5. 2. ed. São Paulo: Editora 34, 2012 (Coleção TRANS).

DELEUZE, Gilles; PARNET, Claire. Diálogos. Tradução de Eloísa Araújo Ribeiro. São Paulo: Escuta, 1998.

FANON, Franz. Os condenados da Terra. Tradução de José Laurênio de Melo. Rio de Janeiro: Civilização Brasileira, 1968.

Pele negra máscaras brancas. Tradução de Renato da Silveira Prefácio de Lewis R. Gordon. Salvador, EDUFBA, 2008.

FOUCAULT, Michel. História da sexualidade 2. O uso dos prazeres. 8. ed. Rio de Janeiro: Graal, 1998.

GROSFOGUEL, Ramón. Para descolonizar os estudos de economia política e os estudos pós-coloniais: Transmodernidade pensamento de fronteira e colonialidade global. In. SANTOS, Boaventura Sousa; MENESES, Maria Paula (Orgs.). Epistemologias do Sul. 2. ed. Coimbra: Almedina, 2010 (Série Conhecimentos e Instituições).

HAESBAERT, Rogério; BRUCE, Glauco. A desterritorialização na obra de Deleuze e Guattari. GEOgraphia. Vol. 4, n. 7, 2002. Disponível em: http://www.uff.br/geographia/ojs/index.php/geographia/article/viewFile/74/72 Acesso em: 03/2018.

HARDT, Michale; NEGRI, Antonio. Império. 2. Ed. Tradução de Berílio Vargas. Rio de Janeiro: Record, 2001. 
LAPOUJADE, David. Deleuze, os movimentos aberrantes. Tradução de Laymert Garcia dos Santos. São Paulo: N-1, 2015.

LE BRETON, David. David Le Breton, sociólogo, antropólogo e psicólogo: 'As condutas de risco são um chamado à vida. Entrevista à Danielle Nogueira, $O$ Globo, 26/03/2017. Disponível em: https://oglobo.globo.com/sociedade/conte-algo-que-nao-sei/david-lebreton-sociologo-antropologo-psicologo-as-condutas-de-risco-sao-um-chamado-vida18902734 Acesso em: 04/2018.

MELVILLE, Herman. Bartleby, The Scrivener: A Story of Wall-Street. The Project Gutenberg. [1853]2005.

NIETZSCHE, Friedrich. Humano demasiado humano: um livro para espíritos livres. Tradução de Paulo César de Souza. São Paulo: Companhia das Letras, 2005.

Assim falava Zaratustra: um livro para todos e para ninguém. Tradução de Mário Ferreira dos Santos. Petrópolis-RJ: Vozes, 2011.

Ecce Homo: como se chega a ser o que se é. Tradução de Antonio Carlos Braga. (Coleção o Essencial de Nietzsche). São Paulo: Escala, 2013a.

. O nascimento da tragédia. Tradução de Antonio Carlos Braga. (Coleção o Essencial de Nietzsche). São Paulo: Escala, 2013b.

A genealogia da moral. Tradução de Antonio Carlos Braga. (Coleção o Essencial de Nietzsche). São Paulo: Escala, 2013c.

QUIJANO, Aníbal. Colonialidad del poder, eurocentrismo e América Latina. In. LANDER, Edgardo. La colonialidad del saber. Eurocentrismo e ciencias sociales: perspectivas latinoamericanas. Buenos Aires: CLACSO, 2000.

Colonialidade do poder e classificação social. In. SANTOS, Boaventura Sousa; MENESES, Maria Paula (Orgs.). Epistemologias do Sul. 2. ed. Coimbra: Almedina, 2010 (Série Conhecimentos e Instituições).

SANTOS, Boaventura de Sousa. Suicídio Coletivo? Folha de São Paulo. mar./2003. Disponível em: < http://www1.folha.uol.com.br/fsp/opiniao/fz2803200309.htm>: Acesso em 02/2018.

Para além do pensamento abissal: das linhas globais a uma ecologia dos saberes. In. SANTOS, Boaventura Sousa; MENESES, Maria Paula (Orgs.). Epistemologias do Sul. 2. ed. Coimbra: Almedina, 2010 (Série Conhecimentos e Instituições).

SZTUTMAN, Renato. A potência da recusa - algumas lições ameríndias. Sala Preta. vol. 13, n. 1, jun 2013, p. 163-182. Dossiê Espetáculo: Recusa.

TÓTORA, Silvana Maria Corrêa. Quid vitae? Uma política dos movimentos aberrantes. Aurora, São Paulo, v.9 n.27, p. 108-113, out. 2016-jan.2017. 
VIVEIROS DE CASTRO, Eduardo. A inconstância da alma selvagem e outros ensaios de antropologia. São Paulo: Cosac Naify, 2002.

Diversidade Socioambiental. In. ISA - INSTITUTO SOCIOAMBIENTAL. Almanaque Brasil Socioambiental. São Paulo, 2008.

. Metafísicas Canibais: elementos para uma antropologia pós-estrutural. São Paulo: Cosac Naify, 2015.

ZOURABICHVILI, François. Deleuze e o possível. In. ALLIÉZ, Éric. Gilles Deleuze: uma vida filosófica. Coordenação de Tradução Ana Lúcia de Oliveira. São Paulo: 34, 2000.

O vocabulário de Deleuze. Tradução de André Telles. Rio de Janeiro: Nova Fronteira, 2004.

Recebido em: 08/11/2018 * Aprovado em: 28/03/2019 * Publicado em: 27/06/2019 